\title{
Sobre o monstro, a natureza e a origem: uma releitura de Frankenstein ou o Prometeu moderno
}

Felippe Cardozo Ciacco

PPGAS-UFSC

\begin{abstract}
Resumo
A estranha figura do mostro, espécie de inclassificável ou lado de fora e margem de toda a classificação, pode se encontrar na encruzilhada de uma série aparentemente dispersa de histórias: história da psiquiatria, do direito religioso ou laico, da criminologia, das representações ocidentais sobre o Oriente, da embriologia, das filosofias políticas conservadoras e mesmo de uma certa literatura. Este ensaio pretende revisitar a figuração do monstro na relação paradoxal que estabelece com o saber: ao mesmo tempo lado de fora do saber, marcador de sua impossibilidade, e princípio de inteligibilidade: chave fundadora do saber psiquiátrico, embriológico, das representações do outro distante. Para explorar tal relação, procura realizar uma breve releitura do clássico Frankenstein or the modern Prometheus.
\end{abstract}

Palavras-chave: monstro; Frankenstein; natureza; genealogia.

\begin{abstract}
The strange figure of the monster, a sort of unclassifiable or outside and margin of every classification, may be found in the path between an apparently disperse series of histories: history of psychiatry, of religious or secular law, of criminology, of the western representations of the East, of embryology, of the conservative political philosophies and even of a certain literature. This essay intends to revisit the figuration of the monster in its paradoxical relation with knowledge: at one time, the outside of knowledge, the sign of its impossibility, and principle of intelligibility: founder key of the psychiatric knowledge, of embryologic knowledge, of the representations of the distant other. To exploit this relation, this paper intents to accomplish a short rereading of the classic Frankenstein or the modern Prometheus.
\end{abstract}

Keywords: monster; Frankenstein; nature; genealogy. 
1. WITTKKOWER, Rudolf. "Marvels of the East. A Study in the History of Monsters". Journal of the Warburg and Courtauld Institutes, 5, 1942, p. 159-197.

2. SHELLEY, Mary. Frankenstein, Or The Modern Prometheus. Engage Books, 2008.

3. NEGRI, Antonio. "El monstruo biopolítico. Vida desnuda y potência”, 2007, p. 93-141.

4. PARK, Katharine; DASTON, Lorraine J. "Unnatural conceptions: the study of monsters in sixteenth-and seventeenth-century France and England". Past \& Present, 1981, p. 20-54.

5. BRAIDOTTI, Rosi. "Signs of wonder and traces of doubt: On teratology and embodied differences", 1999, p. 290-301.
A estranha figura do mostro, espécie de inclassificável ou lado de fora e margem de toda classificação, pode se encontrar na encruzilhada de uma série aparentemente dispersa de histórias: história da psiquiatria, do direito religioso ou laico, da criminologia, das representações ocidentais sobre o oriente, da embriologia, das filosofias políticas conservadoras e mesmo de uma certa literatura. Este ensaio pretende revisitar a figuração do monstro na relação paradoxal que estabelece com o saber: ao mesmo tempo lado de fora do saber, marcador de sua impossibilidade, e princípio de inteligibilidade: chave fundadora do saber psiquiátrico, embriológico, das representações do outro distante ${ }^{1}$. Para explorar tal relação, procuro realizar uma breve releitura do clássico Frankenstein or the modern Prometheus ${ }^{2}$. $O$ interesse que direciono a tal texto, no entanto, se afasta da teoria literária na medida em que tem como base problemas antropológicos, em especial a relação entre a noção de natureza (ou a oposição entre natureza e cultura) e noções de origem e criação na articulação do que poderíamos tomar como teorias genealógicas. A fronteira entre disciplinas, no entanto, tende a se esfumaçar na medida em que alguém se proponha a levar a sério a figura do monstro e seguir os cortes transversais que este opera nas linhas históricas em que atuou e atua.

O monstro pode operar vários problemas distintos: problema de origem e nascimento, problema de classificação, problema quanto a seu estatuto ontológico, problema do crime e das perversões em geral, problema da distância ou das terras distantes, problema, enfim, do próprio saber e de sua possibilidade. Figura multifacetada, difícil de capturar, dispersa no passado longínquo, e muitas vezes infame (pré-científico) de uma série de saberes autônomos entre si, o monstro recentemente parece querer ganhar uma nova vida, recuperado agora como chave ou enigma daquilo que se pode chamar, de maneira bastante provisória, cultura ocidental. Ele reaparece na filosofia política de Toni Negri ${ }^{3}$, nos estudos cada vez mais sistemáticos da história medieval, na história da ciência iluminada pelo feminismo ${ }^{4}$, na filosofia nômade de Rosi Braidotti ${ }^{5}$. Como espécie de impensável, relegado ao lado de fora do logos, como exceção inquietante às leis da natureza, aos poucos parece se tornar objeto de uma nova produção, uma espécie de nova teratologia.

O reaparecimento recente do monstro como possibilidade de pensamento crítico não deve surpreender inteiramente. Por ora, trata-se de apresentá-lo como figura que indicia tanto uma exclusão do domínio da razão quanto da natureza. Trata-se, em suma, de uma figura ligada a uma certa obscuridade, figura noturna, de pesadelo ou terror. Figura desrazoada, mas que se torna contemporaneamente interessante ao colocar em cheque os pressupostos da razão. É que o monstro, durante o 
período medieval e até meados do século XVII europeu, esteve ligado a toda a sorte de fenômenos inexplicáveis: inundações, erupções vulcânicas, ao mesmo tempo que personificado em todo o tipo de nascimento anômalo. O monstro e a catástrofe andaram lado a lado por esses cenários, apontando para fenômenos inexplicáveis, onde o sistema de classificação, os princípios de inteligibilidade, laicos ou religiosos, parecem não poder penetrar. No entanto, o monstro figura como matéria de interpretação, como problema filosófico-teológico desde Aristóteles, passando por Agostinho até Francis Bacon, que acolheu o monstro em seu projeto de filosofia natural ${ }^{6}$. Como signo ou enigma, pode figurar a ira divina, a resposta de Deus, ou de uma natureza personificada, às transgressões humanas. A literatura, majoritariamente de língua inglesa, refere-se ao monstro como wonder, prodigy e portent.

Como signo-mistério, suporte de revelações e anúncio do perigo, do pecado, da transgressão, etc., o monstro esteve próximo das imaginações ligadas ao fantástico. Não à toa, a literatura gótica que emerge no século XVIII europeu foi povoada por monstros: vampiros, fantasmas, demônios. A tradição fantástica, fascinada pelas figuras do horror, da transgressão e da noite, caminhou paralelamente àquela outra, mais conhecida e respeitável, das luzes, como seu contraponto - obscuro, por vezes reacionário, obscurantista e aristocrático, mas como material crítico sempre renovado:

If not a purely negative term, Gothic writing remains fascinated by objects and practices that are constructed as negative, irrational, immoral and fantastic. In a world which, since the eighteenth century, has become increasingly secular, the absence of a fixed religious framework as well as changing social and political conditions has meant that Gothic writing, and its reception, has undergone significant transformations. Gothic excesses, none the less, the fascination with transgression and the anxiety over cultural limits and boundaries, continue to produce ambivalent emotions and meanings in their tales of darkness, desire and power. ${ }^{7}$

Trata-se de uma literatura caracterizada essencialmente como vulgar, em certa medida inaceitável frente aos cânones literários, relegada à marginalidade das revistas, com efeito, extremamente populares. Indigna da alta cultura, os contos de terror espalhados pela Europa no mínimo desde o século XVIII, eventualmente encontrariam seu lugar em obras clássicas, consagradas pela mesma crítica que rejeitou o gótico. O Frankenstein de Mary Shelley ou a obra de Edgar Allan Poe são capazes de fazer algum tipo de justiça ao terror gótico na primeira metade do século XIX.
6. PARK, Katharine; DASTON, Lorraine J. "Unnatural conceptions: the study of monsters in sixteenth-and seventeenth-century France and England". Past \& Present, 1981, p. 20-54.

7. BOTTING, Fred. Gotbic. 2013, p. 1. 
No interior da oposição entre o dia e a noite, a Grande literatura e os romances vulgares e contos impressos em papel barato, a razão e a desrazão, a ordem legítima da natureza e a catástrofe anunciada por sua transgressão, esconde-se a figura do monstro, aparentemente condenada ao esquecimento, relegada aos textos pobres de uma literatura execrável. No entanto, esse regime imaginativo, no qual o monstro ocupa a função de suspender ou radicalizar, não deixou de ser recuperado pelos projetos mais diversos, em contextos políticos, intelectuais, literários tão díspares como a emergência do surrealismo ou a onda atual do antropoceno. Ainda que o monstro não seja levado a sério, suas operações continuam a ressoar, através de sua figura correlata, a catástrofe.

$\mathrm{Na}$ esteira do gótico e partilhando a mesma vulgaridade e irrespeitabilidade, a ficção científica começa em uma equação entre o monstro, o saber (a filosofia natural ou os grandes complexos tecno-científicos, pouco importa) e a catástrofe. É com Mary Shelley e o monstro de Victor Frankenstein que se pode começar a estranha (e controversa) história da ficção científica. Trata-se, em alguma medida, de uma ruptura no interior da literatura fantástica. Conservando os temas góticos, o ambiente de terror, a narrativa catastrófica, a sinistra aliança entre o saber e a monstruosidade, Mary Shelley faz, no entanto, com que o monstro se desloque do nível sobrenatural e passe a operar os problemas de origem que lhe são característicos desde a Idade Média a partir de uma nova chave. O monstro fabricado pelas luzes aponta para a abertura de um campo de imaginação e especulação em grande medida novo, impulsionado pelo galvanismo e pelas estranhas junções entre as novas ciências e o fantástico:

8. SHELLEY, Mary. Frankenstein ou o Prometeu moderno, 2011, p.19.

9. Ibidem, p. 15.

\begin{abstract}
A ocorrência do episódio no qual se baseia esta ficção não é, na opinião do doutor Darwin e de alguns dos autores alemães na área de fisiologia, inteiramente impossível. Não quero dar a impressão de depositar a mais remota fé numa suposição dessas; porém, ao assumi-la como base de um trabalho de ficção, não creio que estivesse apenas entrelaçando uma série de terrores sobrenaturais. ${ }^{8}$
\end{abstract}

O doutor Darwin é Erasmus, o avô de Charles, e na época do Frankenstein (início do século XIX) circulavam rumores na Europa sobre seus experimentos com uma massa de macarrão guardada em um pote de vidro, que "começou, por algum meio extraordinário, a movimentar-se com vontade própria" ". A potência de fabricar vida através da ciência pode certamente ser tomada como um alargamento, mas também uma disjunção em relação ao imaginário gótico. Ainda que a noção de ciência tenha contornos bastante distintos no cenário povoado por Erasmus 
Darwin e Mary Shelley, é notável que através do monstro possa se inaugurar uma nova linhagem de narrativas sobre a ciência.

O monstro como origem da ficção científica desperta, no entanto, controvérsias entre as historiografias da literatura. As hipóteses para um texto original, fundador, proliferam-se quase tanto quanto as obras que pretendem traçar uma história de tal gênero literário. Adam Roberts ${ }^{10}$, por exemplo, pretende ligar a ficção científica às narrativas fantásticas de viagem entre os gregos. Outros procuram começar com Edgar Allan Poe, com Julio Verne ou H.G. Wells. Brian Aldiss ${ }^{11}$ é quem primeiro começa com Mary Shelley. Não estou interessado nas definições e disputas que envolvem a inscrição de um texto como fundador. Tomo Frankenstein, mas, sobretudo com o monstro, como fundador, não para reivindicar a tal texto a legitimidade de uma origem, para estabelecer a fundação de um gênero, mas para apostar na potencialidade da figura do monstro para problematizar as condições de possibilidade e os perigos do saber. Ao invés de buscar uma genealogia da ficção científica através de Frankenstein, é preciso atentar para as teorias genealógicas subjacentes a tal obra.

O romance de Mary Shelley tem como centro o problema da origem: cria um plano de tensão entre o par criador-criatura, desenvolve os problemas éticos, os perigos, etc. O coloca, no entanto, a partir de um dispositivo novo, que será exaustivamente recuperado, modificado, radicalizado, seja na ficção ou na filosofia, na história das ciências ou na ecologia. É o monstro que está no centro desse dispositivo.

Victor Frankenstein, o Prometeu moderno, de acordo com o título, é quem dá vida ao monstro, não por procedimentos mágicos ou alquímicos, mas servindo-se dos recursos de ponta da filosofia natural do século XVIII, levando a cabo, ainda que de maneira sombria, o sonho galvanista.

Se Mary Shelley evoca Erasmus Darwin para afastar Frankenstein do regime dos "terrores sobrenaturais", é preciso insistir em tal novidade em relação ao romance gótico e explorar os modos pelos quais o monstro opera tal disjunção, assim como talvez seja possível deslocar o problema do sobrenatural para o da conceituação da natureza ${ }^{12}$. O monstro, agora, passa a ser um outro tipo de personagem, ainda que possa ser descrito nos mesmos termos do monstro em geral, ou da noção de monstro que se tem na Europa da Idade Média até o século XVIII. Michel Foucault faz a genealogia do monstro, em um de seus cursos no College de France, seguindo sua marcha progressiva rumo aos braços da psiquiatria nascente, ou, se quisermos, rumo aos portões do hospício:

O monstro, da Idade Média ao século XVIII de que nos ocupamos, é essencialmente o misto. É o misto de dois
10. ROBERTS, Adam. The

history of science fiction, 2005.

11. ALDISS, Brian W. "with David Wingrove”, 1986.

12. Park e Daston mostram como o monstro ocupa papel de destaque nas filosofias da natureza até Francis Bacon, como caso limite, excepcional, mas ao mesmo tempo fundamental para o entendimento da natureza. De acordo com o argumento das autoras, a progressiva desaparição do monstro das preocupações intelectuais modernas acompanha à passagem de uma noção de natureza personificada a uma outra, imanente. PARK, Katharine; DASTON, Lorraine J. "Unnatural conceptions: the study of monsters in sixteenthand seventeenth-century France and England", 1981, p. 20-54. 
13. FOUCAULT, Michel. Os anormais. 2001, p.79.

14. Ibidem, p. 70 .

15. TURNER, Victor. Floresta de simbolos: aspectos do ritual Ndembu, 2005, p.150. reinos, o reino animal e o reino humano: o homem com cabeça de boi, o homem com pés de ave - monstros. É a mistura de duas espécies: o porco com cabeça de carneiro é um monstro. É o misto de dois indivíduos: o que tem duas cabeças e um corpo, o que tem dois corpos e uma cabeça, é um monstro. É o misto de dois sexos: quem é ao mesmo tempo homem e mulher é um monstro. É um misto de vida e de morte: o feto que vem à luz com uma morfologia tal que não pode viver, mas que apesar dos pesares consegue sobreviver alguns minutos, ou alguns dias, é um monstro. ${ }^{13}$

O monstro é, portanto, essa figura que desafia a própria figuração - na medida em que justapõe de maneira aberrante figuras de domínios distintos -, que coloca em questão os quadros de classificação, enquanto espécie de inclassificável ou de figura liminar. Exceção da natureza, o monstro torna-se também problema ou até mesmo enigma jurídico, seja de direito civil ou religioso: pode o hermafrodita ser batizado? Deve receber herança? Sabemos que até o início do século XVII os hermafroditas (monstros) eram executados, em geral queimados. Esse problema jurídico, no entanto, não deve nos deter excessivamente. A importância da dupla transgressão que representa o monstro, da natureza e do direito, é o de combinar "o impossível e o proibido" ${ }^{14}$.

Enquanto entidade que suspende a classificação, que ameaça a lei natural e a lei humana ou divina, o monstro carrega, encarna, todas as irregularidades, os desvios, as forças do caos e da catástrofe: figura composta por uma desfiguração, o monstro se torna, paradoxalmente, princípio de inteligibilidade. Victor Turner chamou a atenção para o monstro, figurado no sacra, nesse mesmo sentido: figura que aglutina exageradamente dois domínios e assim funciona pedagogicamente, "para ensinar os neófitos a distinguir claramente entre os diversos fatores da realidade, tal como é concebida em sua cultura"15. No caso da Idade Clássica europeia, o monstro é o que estará na base de todos os problemas de anomalia. Inclassificável, é ao mesmo tempo a forma de classificação por excelência de todo o domínio disperso do negativo e colaborará, assim, com o nascimento e a consolidação da psiquiatria.

Isso (a psiquiatria) não é o que nos preocupa no momento, mas sim o emprego do monstro em Frankenstein e toda a potência que essa curiosa entidade pode liberar. O monstro, é quase desnecessário dizer, possui grande afinidade com o fantástico, o sobrenatural (ou talvez com o infranatural). No entanto, retornando ao comentário de Mary Shelley, podemos verificar que o monstro faz aparecer uma problemática que se desloca da problemática do sobrenatural, apontando para uma noção imanente de natureza. Em outras palavras, não é a figura do monstro que é novidade em Frankenstein, mas o campo em que 
este se inscreve, o procedimento que é posto a operar. Se o romance pode se inscrever na linhagem de terror gótico que o inspira, faz esse terror passar a outro plano. É precisamente a origem do monstro, como se pode adivinhar, que cria este novo plano para os terrores que o monstro desperta. $\mathrm{O}$ monstro de Victor Frankenstein não é uma aberração da natureza nos mesmos termos que o hermafrodita, o homem com pé de galinha ou os gêmeos siameses, que atormentam o imaginário ocidental da Idade Clássica. Ainda que todos os personagens anteriores atestem, em sua origem, uma violação das leis da natureza e das leis divinas (Foucault mostra como o discurso da época liga a aparição do monstro frequentemente à zoofilia), a origem do monstro de que tratamos implica uma violação da natureza de uma ordem totalmente distinta. Como sublinhado anteriormente, o saber e a ciência, encarnadas em Victor Frankenstein, estão na origem da monstruosidade.

A novidade para que chamamos a atenção no romance consiste em fazer de sua trama a conjunção entre a ciência e a monstruosidade. Pouco importa para nossos interesses se a massa de macarrão de Erasmus Darwin de fato se moveu, ou se os fisiologistas do início do século XIX tinham razão em supor que seria possível realizar as aspirações galvanistas. Talvez tais relatos não passassem de metaficções de Shelley. O sobrenatural não é deslocado pelas assertivas dos filósofos da natureza, tampouco pelo experimento do avô de Darwin, mas pelos procedimentos narrativos da obra em questão. $\mathrm{O}$ impossível e o proibido são colocados em relação à ciência, de maneira a produzir circuitos catastróficos. Antes de seguir, consultemos por um instante a literatura, para poder melhor apreender as condições e os termos de tal conjunção.

Jean Jacques Lecercle já havia problematizado a figura do monstro em seu livro sobre Frankenstein ${ }^{16}$, desde uma certa concepção de mito, forjada pelo autor em uma leitura de Lévi-Strauss à luz de Marx e Freud. A definição de mito, mais ou menos frankensteiniana a que chegamos é a seguinte: "O mito não é só a solução imaginária de uma contradição real insolúvel; também é a familiarização (a sexualização) da conjuntura histórica, assim como é a historicização da conjuntura familiar (sexual)"17. Vejamos como o autor decompõe estes termos na leitura, de resto bastante interessante, que faz de Frankenstein.

Solução imaginária de uma contradição real insolúvel. Lecercle traça de maneira bastante detalhada a conjuntura histórica em que a obra de Mary Shelley vem ao mundo, mostrando como a metáfora do monstro pode estar ligada historicamente ao terror que se sucede à Revolução Francesa. Victor Frankenstein, nesse sentido, pode representar o ideal das luzes, o movimento revolucionário, inspirado pela filosofia e pelas ciências ("mas que
16. LECERCLE, Jean-Jacques. Frankenstein, mito y filosofía, 2001, p. 65.

17. Ibidem, p. 66. 
18. SHELLEY, Mary.

Frankenstein ou o Prometeu moderno, 2011, p. 48. glória coroaria minha descoberta se eu fosse capaz de acabar com as doenças do corpo humano e tornar o homem invulnerável" $\left.{ }^{18}\right)$, mas que ao dar cabo a seus projetos, ao concluir sua criação, produz, à revelia de suas boas intenções, um monstro. Oscilação, portanto, entre os princípios e os resultados, entre o entusiasmo pelos ideais da revolução e os perigos de seus desdobramentos. Oscilação que marcaria a própria posição de Mary Shelley, exilada em Genebra, já que levanta suspeitas de jacobina na Inglaterra e de girondina na França. Oscilação, ao mesmo tempo, das entidades a que o monstro pode fazer referência. No argumento de Lecercle o monstro oscila entre a representação da massa revolucionária e a representação de Napoleão, o herdeiro ilegítimo da Revolução.

Se o monstro pode representar as massas, o horror e a violência desencadeadas pela encarnação/massificação das ideias revolucionárias, poderíamos aproximar Mary Shelley dos conservadores que temem o povo, tal como Edmund Burke ou mais tarde Alexis de Tocqueville. Assim, o Frankenstein, dotado de tons aristocráticos, reencenaria os temas românticos, agora carregados pelo medo reacionário que a Revolução Francesa inspira. O próprio Lecercle rejeita tal interpretação, que apaga a tensão da posição de Mary Shelley no interior da trama política, posição que pode ser melhor compreendida através de sua própria genealogia. Mary é filha de William Godwin e Mary Wollstonecraft. Godwin está imerso no meio iluminista inglês, é filósofo político, autor de Inquiries into Political Justice, enquanto Wollstonecraft é autora de Vindication of the Rights of Woman, avó do feminismo. Ambos são entusiastas da revolução, e se a posição de Mary pode oscilar entre a fascinação e o medo das massas, está longe da posição aristocrática ou decididamente conservadora. Lecercle justapõe, portanto, em sua interpretação do monstro, a linha histórica que faz referência ao momento tenso que se sucede à revolução e seus efeitos napoleônicos à linhagem familiar, fazendo o texto funcionar como resolução imaginária das contradições desencadeadas pelo processo revolucionário, mas, ao mesmo tempo, como familiarização do processo histórico, isto é, como leitura das contradições históricas situada pela economia familiar (biográfica) da autora.

Lecercle produz, portanto, duas séries narrativas que passam a balizar sua interpretação do texto de Shelley, uma histórica e outra biográfico-familiar. O texto se torna, assim, uma espécie de espelho (é esta a expressão do autor) que justapõe/reflete as duas séries. $\mathrm{O}$ monstro, reduzido à metáfora, parece perder algo de sua potência e nós parecemos, com isso, perder algo que está no centro de Frankenstein, nos procedimentos genealógicos que engendra, para recorrer a noções genealógicas que lhe são, em última instância, exteriores. Monstro condicionado 
pela história, monstro edipianizado e sexualizado (voltaremos a este ponto), tal qual aqueles outros monstros que, banalizados, passam ao regime psiquiátrico-asilar. A leitura excessivamente centrada na figura da autora, e nas metáforas que revelam a um só passo a historicidade de sua posição biográfica-familiar e a leitura biográfica-familiar que está fadada a fazer da história, pode ser deslocada seguindo as tensões que envolvem o par criador-criatura, gênio-monstro.

É verdade que Lecercle não perde de vista a temática genealógica e procura tratar Frankenstein como mito de criação, ainda que deformado. No entanto, a descrição do ato de criação que o autor faz nos parece um tanto quanto difícil de seguir:

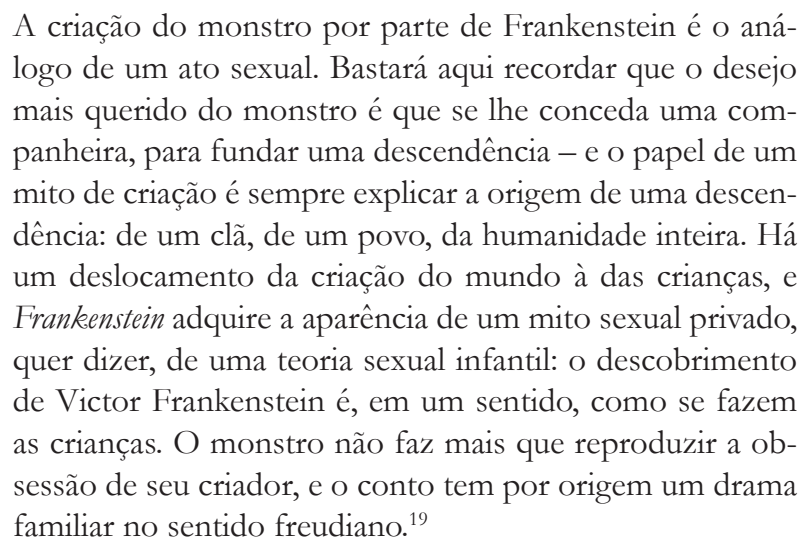

O ato assexuado de criação (imaginário) substitui o ato real da criação sexuada. Por um procedimento de redução, a conjunção entre ciência e monstruosidade desaparece para dar lugar a uma teoria oculta da sexualidade. Conto da cegonha, ou mito de Édipo, o monstro de Frankenstein perde suas forças, torna-se uma espécie de representação da representação, rearticulação mais ou menos imperfeita de um antigo problema. A leitura que procuro desenhar aqui, pretende, antes, seguir a singularidade dos procedimentos de criação narrados em Frankenstein. A disrupção que acompanha o nascimento e que produz uma série caótica de componentes, que acabam por engendrar a catástrofe, o perigo e a morte, está marcada pela supressão do elemento sobrenatural e pelo protagonismo do saber e da técnica. Victor descreve o momento que precede imediatamente à criação: "Com uma ansiedade que beirava a agonia, reuni ao meu redor os instrumentos necessários, de modo a poder infundir uma centelha de vida ao ser inanimado que jazia a meus pés"20.

A artificialidade tecnocientífica do procedimento de criação, antes de fazer referência ao problema pretensamente universal da criação/concepção, o faz passar do nível biológico ao histórico, enquanto ruptura, enquanto concepção singular que abala o regime genealógico natural (sexuado). Estamos mais
19. LECERCLE, Jean-Jacques. Frankenstein, mito y filosofia, 2001, p.19-20.

20. Ibidem, p. 66. 
21. LATOUR, Bruno. Jamais fomos modernos, 1994, p. 48.

22. SHELLEY, Mary.

Frankenstein ou o Prometeu moderno, 2011, p. 46.

23. Ibidem, p. 60.

24. Ibidem, p. 63. próximos das narrativas fantásticas em torno da zoofilia do que dos problemas freudianos: não se trata da substituição da concepção natural por uma outra, mais ou menos lúdica, de natureza instrutiva ou exemplar, exagerada ou caricatural, mas de tornar pensável um novo dispositivo genealógico. Trata-se de um procedimento que, com horror, imagina-se a probabilidade histórica - ou que, ao menos, torna-se historicamente imaginável. A introdução do problema da ciência, das luzes e de seus possíveis monstros, passa pela Revolução Francesa, como sublinhado por Lecercle, mas não se reduz a ela. Se o monstro coloca em cheque a lei natural, em Frankenstein o que está em jogo é uma noção secularizada de natureza, cuja oposição ao reino dos homens entre $\mathrm{si}^{21}$ oferece as bases para a transgressão em que se centra a trama. Não estamos simplesmente no nível das tensões entre o Novo e o Antigo regime, mas em uma conjunção (ciência-monstro) que faz com que a jurisdição do poder possa ser imaginada em registros até então inacessíveis.

Frankenstein opõe o tempo todo o domínio humano ao domínio da natureza, para fazê-los, depois, voltarem-se um contra o outro. Victor confessa que:

nem a estrutura das línguas, nem os sistemas de governo e nem a política de vários estados possuíam atrativos para mim. Eram os segredos do céu e da terra que eu desejava aprender; e quer me ocupasse da substância visível das coisas, quer do espírito interior da natureza e da alma misteriosa do homem, ainda assim minhas pesquisas voltavam-se para a metafísica, ou, num sentido mais elevado, para os segredos físicos do mundo. ${ }^{22}$

Da natureza purificada, das coisas tornadas objeto e do mundo decifrável da física surgem as condições de possibilidade da empreitada frankensteiniana. Natureza-segredo, mas, acima de tudo, natureza-decifrável, objeto do saber. O segredo, aqui, já não tem mais os ares do mistério, e a narrativa não cansa de sublinhá-lo: "A escuridão não tinha qualquer efeito sobre minha imaginação, e os cemitérios eram, para mim, meros depósitos de corpos privados de vida, que de moradia da beleza e da força, haviam se tornado comida para os vermes"23, esclarece Victor. Do processo de desvelamento de segredos secularizados, encontramos as ressonâncias que talvez possam justificar a referência prometeica do título: "pensei que, se podia conferir vida à matéria inanimada, talvez pudesse, com o tempo (embora agora saiba que é impossível), devolver a vida aos corpos que a morte aparentemente devotara à corrupção"24.

A separação entre o mundo da natureza e o mundo social ou humano, no entanto, oferece apenas o cenário inicial em Frankenstein, o cenário, poderíamos dizer, que precede a criação. 
Não é difícil adivinhar que o momento em que a produção empreendida por Frankenstein é concluída marca o grande ponto de inflexão no texto. É então que tudo começa a desandar para Victor. O ideal prometeico ${ }^{25}$ de conquista da natureza fracassa no mesmo instante em que o criador assiste, perplexo, aos "olhos amarelos e opacos da criatura se abrirem"26. Frankenstein abandona o cômodo-laboratório, "incapaz de suportar o aspecto do ser que criara", para retornar mais tarde, e então contemplar, "à luz amarelada e fraca da lua, que penetrava no quarto através da veneziana da janela, aquele infeliz - o monstro miserável que $[. .$.$] criara"27.$

A disjunção entre a natureza e o humano (ou a sociedade) é o que produz, então, a conjunção entre ciência e monstruosidade, o ato singular de criação frankensteiniano. O que se sucede à criação são dois movimentos correlatos de fuga. Victor Frankenstein foge de sua criação, acometido de horror. O monstro, abandonado, passa a fugir dos humanos, que para o perseguirem, escandalizados, basta o primeiro contato visual. O duplo movimento de fuga terá como consequência o reencontro catastrófico entre o reino da natureza e o da sociedade, através dos crimes cometidos pelo monstro. A conjunção entre criador e criatura, ciência e monstro, passa a comportar um processo disjuntivo, no momento em que a criatura se volta contra o criador, em uma implacável vingança: “Oprimido pelas memórias dos infortúnios passados, comecei a pensar na sua causa - o monstro que eu criara, o demônio miserável que eu libertara no mundo e que era o responsável pela minha própria destruição" 28 . O romance comporta, portanto, dois movimentos de inversão: a disjunção natureza-sociedade passa a comportar uma síntese conjuntiva na forma da destruição e do crime (o produto tecnocientífico entra no socius), formando a conjunção entre ciência e monstro; a conjunção criador-criatura passa a comportar um movimento disjuntivo na medida em que a criatura se torna irredutível ao criador (incontrolável e perigosa).

O monstro, na medida em que ocupa, por sua própria definição, este lugar liminar, de inclassificável, permite a questão de seu estatuto ontológico. É notável que a criatura produzida por Victor Frankenstein não tenha nome, sendo designada durante todo o romance como monstro, demônio, ou criatura maligna. É o próprio monstro quem formula o problema ontológico, de maneira assaz sugestiva: "E o que era eu? [And what as I?]"29. O pronome empregado pelo monstro problematiza seu próprio estatuto: criação antropomórfica, humanoide, ainda assim, desprovida do estatuto de pessoa? O monstro parece condenado a ficar sempre a meio caminho entre o mundo das coisas e o das pessoas, e é precisamente sua liminaridade que faz a natureza e a sociedade se encontrarem na forma aberrante do crime.
25. “...o 'excepcionalismo humano' é um autêntico estado de exceção ontológico, fundado na separação autofundante entre Natureza e História. A tradição militante de tal dispositivo mítico é a imagem prometeica do homem conquistador da natureza". DANOWSKI, Déborah; VIVEIROS DE CASTRO, Eduardo. Há mundo por vir? Ensaio sobre os medos e os fins, 2014, p. 43.

\section{SHELLEY, Mary.}

Frankenstein ou o Prometeu moderno, 2011, p. 63.

27. Ibidem, p. 67.

28. Ibidem, p. 218.

29. Ibidem, p.134. 
30. Ibidem, p. 191.

31. Muitas são as ressonâncias com o tema do privilégio da identidade. DELEUZE, Gilles. Diferença e repetição, 1988,

32. NEGRI, Antonio. "El monstruo biopolítico. Vida desnuda y potencia”, 2007, p. 94.

33. Ibidem, p. 95.

34. DELEUZE, Gilles; GUATTARI, Félix. Kafkea: por uma literatura menor, 1977.

35. NEGRI, Antonio. "El monstruo biopolítico. Vida desnuda y potencia", 2007, p. 95.
O monstro não pode sequer ser responsabilizado pelos crimes, dado o caráter inverossímil de sua existência: "Será que alguém além de mim, o criador, na verdade acreditaria, a menos que seus sentidos o convencessem, na existência do monumento vivo da presunção e ignorância que eu soltara no mundo?"30

Toni Negri procurou mostrar, em um texto de 2001, como a eugenia está intimamente ligada à fundação da metafísica ocidental, através da coincidência entre o belo, o bom e a verdade ${ }^{31}$, de modo que "do outro lado, está o monstro" 32 . O monstro, assim, estaria inscrito como figura da exclusão na ontologia ocidental desde Platão. "O monstro está fora da economia do ser" "33: a exclusão do monstro funda, no mundo clássico, a verdade do ser e a origem eugênica da autoridade. Esse princípio, segundo Negri, se atualiza em uma história tão longa como a história da Razão, de modo que seria possível reler tal história do ponto de vista do monstro. Negri, procura, assim, elevar o monstro ao estatuto de categoria político-revolucionária, que denuncia a origem da autoridade ao mesmo passo que se situa no registro de uma outra genealogia possível: anti-humanista, contra-universal.

Não nos interessamos, aqui, em fazer através de Negri uma grande totalização da história ocidental, encarnada na figura negativa do monstro, mas em nos valer do estatuto deontológico do monstro, em apostar, como Negri, no seu potencial político, ainda que tomemos um caminho distinto. $\mathrm{O}$ monstro de Frankenstein, exilado entre os humanos e as coisas, cataliza uma outra teoria da origem: conjuga a origem e o perigo sob o avatar da ciência. O monstro, a figura do negativo, permite criar um agenciamento da enunciação ${ }^{34} \mathrm{em}$ que o saber e a razão não apenas aparecem intimamente ligados ao poder e a um poder tão verdadeiramente incontrolável quanto perigoso, mas em que aparecem como entidades problematizáveis. A origem que se inscreve com o monstro abala todo o bom nascimento ${ }^{35}$ possível. O monstro como princípio de inteligibilidade, aqui não serve mais aos desdobramentos eugênicos inscritos na noção de anomalia, mas ameaça, através da vingança, todo o poder soberano, inclusive o da ciência que o produz. Se o monstro está pleno de historicidade, pode agenciar novas linhas históricas que se aproximam da catástrofe ou da escatologia.

O monstro exilado, a meio caminho entre o humano e o inumano, que empreende sua brutal vingança contra a humanidade que a um só passo o cria e o exclui, pode ser, de fato, remetido a algum tipo de mito de origem, como queria Lecercle. O monstro de Frankenstein, ao que parece, pode estar nas bases de uma longa linhagem de personagens: $\mathrm{o}$ androide, a inteligência artificial em geral, o robô, o zumbi. Série estranha que passa a povoar o imaginário literário, mas também político, dos mo- 
dernos. Seres intermediários, humanoides fabricados em laboratórios de grandes corporações, nunca inteiramente controláveis, sempre algo ameaçadores. A disjunção entre criatura-criador na teoria genealógica de Frankenstein não está distante de se atualizar no imaginário atual. Basta pensar na ideia fulminante de Gaia $^{36}$, tentativa de deslocamento atual da noção moderna de natureza, que coloca em questão os modos de produção do saber e de intervenção técnica através do imaginário escatológico engendrado pela crise ecológica.

Antropoceno, capitaloceno, Ctuloceno, Gaia, humanos e terranos, cyborgues, alguns dos autores atuais se aproximam do mito e também da ficção científica. Em Há mundo por vir?, Danowski e Viveiros de Castro descrevem seu empreendimento da seguinte maneira: "Esse texto é uma tentativa de levar a sério os discursos atuais sobre o 'fim do mundo' [...] como tentativas de invenção, não necessariamente deliberadas, de uma mitologia adequada ao presente" ${ }^{37}$. Donna Haraway, que sempre soube aproveitar em sua crítica as invenções da ficção científica, atenta para a aproximação entre story e theory: "we need stories (and theories) that are just big enough to gather up the complexities and keep the edges open and greedy for surprising new and old connections" 38 .

\section{Referências}

ALDISS, Brian W.; WINGROVE, David. Trillion Year Spree: The History of Science Fiction. Londres: Gollancz, 1986.

BOTTING, Fred. Gothic. Oxford: Routledge, 2013.

BRAIDOT'TI, Rosi. "Signs of wonder and traces of doubt: On teratology and embodied differences". In: PRICE, Janet e SHILDRICK, Margrit (ed.). Feminist theory and the body: A reader. New York: Routledge, 2013, p. 290-301.

DANOWSKI, Déborah; VIVEIROS DE CASTRO, Eduardo. Há mundo por vir? Ensaio sobre os medos e os fins. Florianópolis: Cultura e barbárie - Instituto Socioambiental, 2014.

DELEUZE, Gilles. Diferença e repetição. Rio de Janeiro: Graal, 1988.

DELEUZE, Gilles; GUATTARI, Félix. Kafka: por uma literatura menor. Rio de Janeiro: Imago, 1977.

FOUCAULT, Michel. Os anormais. Tradução de Eduardo Brandão. São Paulo: Martins Fontes, 2001.
36. DANOWSKI, Déborah; VIVEIROS DE CASTRO, Eduardo. Há mundo por vir? Ensaio sobre os medos e os fins, 2014; LATOUR, Bruno.

"Waiting for Gaia. Composing the common world through arts and politics", 2012, p. 515-538; HARAWAY, Donna. "Anthropocene, Capitalocene, Plantationocene, Chthulucene: Making Kin". Environmental Humanities, n. 6, 2015, p. 159-165; STENGERS, Isabelle. "Accepting the reality of Gaia: A fundamental shift?", 2015, p. 134 .

37. DANOWSKI, Déborah; VIVEIROS DE CASTRO, Eduardo. Há mundo por vir? Ensaio sobre os medos e os fins, 2014, p. 17.

38. HARAWAY, Donna. "Anthropocene, Capitalocene, Plantationocene, Chthulucene: Making Kin". Environmental Humanities, n. 6, 2015, p. 160. 
HARAWAY, Donna. "Anthropocene, Capitalocene, Plantationocene, Chthulucene: Making Kin". Environmental Humanities, v. 6, p. 159-165, 2015.

LATOUR, Bruno. Jamais fomos modernos. Tradução de Carlos Irineu da Costa. Rio de Janeiro: Editora 34, 1994.

"Waiting for Gaia. Composing the common world through arts and politics". In: YANEVA, Albena e ZAERAPOLO, Alejandro (eds.). What is Cosmopolitical Design? Farnham: Ashgate, 2015, p. 21-33.

LECERCLE, Jean-Jacques. Frankenstein, mito y filosofía. Buenos Aires: Nueva Visión, 2001.

NEGRI, Antonio. "El monstruo biopolítico. Vida desnuda y potencia”. In: RODRÍGUES, Fermín e GIORGI, Gabriel (comp.). Ensayos sobre biopolítica. Excesos de vida. Buenos Aires: Paidós, 2007.

PARK, Katharine; DASTON, Lorraine J. "Unnatural conceptions: the study of monsters in sixteenth-and seventeenth-century France and England". Past \& Present, n. 92, p. 20-54, 1981.

ROBERTS, Adam. The history of science fiction. Londres: Palgrave Macmillan, 2005.

SHELLEY, Mary. Frankenstein ou o Prometeu moderno. Rio de Janeiro, Nova Fronteira, 2011

2008.

. Frankenstein, Or The Modern Prometheus. Engage Books,

STENGERS, Isabelle. "Accepting the reality of Gaia: A fundamental shift?”. In: HAMILTON, Clive et al. The Anthropocene and the Global Environmental Crisis: Rethinking Modernity in a New Epoch. New York: Routledge, 2015.

TURNER, Victor. Floresta de simbolos: aspectos do ritual Ndembu. Rio de Janeiro: EdUFF, 2005.

WITTKOWER, Rudolf. "Marvels of the East. A Study in the History of Monsters". Journal of the Warburg and Courtauld Institutes, n. 5, p. 159-197, 1942. 